\title{
Catholic Healthcare Organizations and the Articulation of Their Identity
}

\author{
Martien A. M. Pijnenburg · Bert Gordijn · Frans J. H. Vosman · \\ Henk A. M. J. ten Have
}

\section{Introduction}

This paper deals with the question whether, and if yes, why it is relevant for contemporary Catholic healthcare organizations (HCOs) to articulate their Catholic identity. This question relates to a more encompassing issue: the meaning of institutional Catholic identity against the contemporary backdrop of scientific and rational approaches to health problems, religious and moral pluralism, secularization, increasing influence of markets, and a decline in religious callings.

We will answer this question from three different perspectives: an organizational one by means of interviews, an ecclesiastical by means of magisterial teaching, and a philosophical one referring to Charles Taylor. The answers found in these three perspectives will be compared. The discussion will highlight two specific reasons in favor of an articulation of Catholic identity. First, it enables Catholic HCOs to contribute to the primary objective of the medical-ethical teaching of the Church: to sustain a healthcare practice that gives due right to the dignity of human beings. Second, by articulating their identity Catholic HCOs can perform an

Martien A. M. Pijnenburg, Radboud University Nijmegen Medical Centre, Department of Ethics, Philosophy and History of Medicine, Internal code: 137 EFG, P.O. Box 9101, 6500 HB Nijmegen, The Netherlands; email:m.pijnenburg@efg.umcn.nl.

Bert Gordijn, Radboud University Nijmegen Medical Centre, Department of Ethics, Philosophy and History of Medicine, Internal code: 137 EFG, P.O. Box 9101, 6500 HB Nijmegen, The Netherlands; email: b.gordijn@efg.umcn.nl.

Frans J. H. Vosman, Tilburg University, Faculty of Humanities, Department of Religious Studies and Theology, P.O. Box 90153, 5000 LE Tilburg, The Netherlands; email: F.J.H.Vosman@uvt.nl.

Henk A. M. J. ten Have, Radboud University Nijmegen Medical Centre, Department of Ethics, Philosophy and History of Medicine, Internal code: 137 EFG, PO Box 9101, 6500 HB Nijmegen, The Netherlands; email:h.tenhave@efg.umcn.nl. 
exemplary role in contemporary pluralistic society on humanity and justice in healthcare.

\section{Interviews}

\section{Background}

The Catholic identity of a $\mathrm{HCO}$ can be expressed in many ways: actual behaviors, organizational culture, religious symbols, architecture. However, these expressions are not 'articulations of identity' in our understanding of the word. In the course of this paper we will elaborate on the concept of 'articulation', but we start with a working definition: articulation is the expression of something in a coherent verbal form, for instance our feelings. According to this definition, the information a Catholic organization provides on its website concerning its Catholic identity is a way of articulating. We employed this working definition in interviews in the U.S., in the autumn of 2005.

Catholic HCOs in the U.S. present an instructive case for learning about the relevancy of articulating. They constitute the largest group of non-profit health care sponsors, systems, and facilities in the U.S. (Dougherty, 2004, p. 181; Pellegrino, 2004, p. 1; Catholic Health Association, 2007). At the same time they experience their Catholic mission to be under pressure, among others by social groups like Merger Watch, that fight faith-based restrictions in providing certain services in, for instance, reproductive healthcare or in end-of-life care decisions (Merger Watch, 2007). Great pressure also comes from a strongly market-oriented society. Market-forces, however, also encourage religious organizations to 'sell' religion. This is one of the explanations why the U.S. contradicts the wide spread assumption that modernization automatically leads to secularization (Halman, Luijkx \& Zundert, 2005, p. 61; Zuckerman, 2004). Another explanation is sought in the constitutional separation between church and state. As Wills puts it: "Thrown back on themselves, the churches were encouraged to search for their own essence, make their moral case on truly religious grounds, reward people in the proper spiritual currency" (1990, p. 383). Because of the presence of this complex of opposing and reinforcing factors, it is instructive to see how and why Catholic HCOs in the U.S. articulate their identity.

The objective of the interviews was to collect ideas for reflection on these questions. The results are not intended to be representative for the U.S. in general, nor for all Catholic healthcare facilities, and even not for the HCOs that were involved. But the results help to deepen our understanding of whether, and why it is relevant to articulate identity. 


\section{Articulation on websites}

Five Catholic HCOs were involved: three hospitals, a health system and a healthcare association. We shall denote the last two as 'member organizations'.

Websites are easily accessible, and meant to inform a broad public about, among other issues, mission, vision and values of the organization. Mission defines its reason to exist. Vision formulates the kind of organization it intends to become. Values represent the deeply held beliefs of the organization with respect to how it expects everyone to behave (Glossary, 2007).

On the websites we visited these distinctions are not always sharp. ${ }^{1}$ What one organization has formulated under mission, another has formulated under vision. Sometimes values are presented separately, sometimes as part of the mission. For our purposes, these differences are less important. Our main interest is what these websites articulate with respect to the Catholic identity of the organization. Three coherent elements can be distinguished.

The first element consists of the basic commitments of the organization. They refer to special groups, like all persons that need special attention, or persons that are poor and vulnerable. Websites also refer to primary tasks like the promotion of health through education, research and patient care; the promotion of the common good; or the task to act in communion with the Church.

The second element is the religiously inspired background. Some refer to the Gospel by expressing the goal to affirm the Good News, or to carry out the healing mission of Jesus and the Church. Other organizations present their history of spiritually motivated care by telling about their founders. The two member organizations articulate their background as a ministry of the Church.

The third element contains the core values. They encompass a wide range of values: respect, integrity, compassion, excellence, knowledge, service to others, heritage, trust, integrity, sense of team, accountability, joy, care, service to the poor, reverence, wisdom, dedication and creativity.

Both member organizations also offer information about Catholic views on medical ethics and social justice, as a way to support and educate their members.

\section{Interviews: method}

In total 27 persons were interviewed about what the organization they work for has articulated on its website. 
Most of the interviewees had a leading position and a specific responsibility with regard to the Catholic identity and mission of their organization. Twelve were members of, or closely affiliated to the board. Six were closely involved in developing institutional ethics policies, for instance as chairman of the ethics committee. Five had a management function in the field of medicine, nursing or pastoral care. Finally, four were working as practitioners. All of the interviewees were believers, most of them Catholic, and ten belonged to a religious congregation as priest, nun or friar.

The interviewees had been informed in advance about the main theme to be discussed: the articulation of Catholic identity. Whether and why is it relevant, how is it perceived in a pluralist environment, and how is it implemented? All interviews were recorded and transcribed. In advance, the interviewees were asked if they consented with this procedure, which they all did. The length of the interviews was between 30 and 60 minutes.

The interviews were semi-structured. There was one main theme to be discussed, but dependent on the interviewee's function, interests, and the course of the interview, some aspects received more attention than others.

To prepare the interviews, we focused on mission, vision and value statements on the website of their organization that were clearly related to the Catholic identity. The website-information was used as interview material. With regard to the analysis of the interviews, we proceeded in several steps. First, we did a close reading of the transcribed interviews, searching for passages with statements about articulation. Second, we coded all statements with regard to identity articulation. Third, we selected coded statements that recurred regularly, or that expressed a specific reason of the interviewee to attach high importance to articulating identity. Finally, we headed the coded statements under seven considerations expressed by the interviewees with regard to the relevancy of articulating Catholic identity.

\section{Results}

We will present the seven considerations, and clarify them by inserting illustrative quotes. ${ }^{2}$

1. Communication: mission, vision and values tell everyone inside and outside the organization what kind of organization it is. It is a way to express "who we are". One of the member organizations values articulation as a way to express the "charismas of the sponsoring organizations".

2. Integrity: interviewees define this as the congruence between the kind of organization it claims to be and its actual performances. They emphasize that articulation of identity is to ensure its integrity, not to outline what makes this organization different from others: "Difference is not the 
important issue; our integrity is." A clear articulation of mission and values offers a criterion to judge an organization's integrity: "It is your framework for action, and for measuring your achievements. Not just of what you are doing, but how you are doing it. It is your moral foundation. How can you know that you did a good job, when you haven't said what you're about?" Articulation of mission presents an enduring "call to integrity." That is why one interviewee said that the only way to understand mission is "to understand it backwards, from your behavior".

3. Inspiration: you do not only have to make clear what you do, but also why you do it, and why all people working in the organization do it. A clearly articulated mission statement "is the container of meaning for people's work. It gives meaning to the people within the organization and to the place of the organization in the whole context of the larger society. (...) They got committed to the mission and bound, as leader and follower, to something that transcends them both but to which they are totally committed. This is what energizes an organization. It also is the basis of the relationships between and among all the employees. They are bound not because they like you, but because they are committed to the same mission." A shared inspiration can strengthen the internal cohesion of an organization. The effect on Catholics will be stronger than on non-Catholics, but the latter might be inspired by the stated values, since a Catholic source of inspiration is not a conditio sine qua non for offering care that reflect these values: "On the practical level, other institutions could say the same thing, from their own perspective." This means, that much of what Catholic hospitals do in everyday practice is not considered to be an exclusive Catholic hallmark.

4. Invitation: articulating identity is meant to invite people, whatever their beliefs, to commit themselves to the organization. This invitation can take different forms. A more passive form is to express that people of all religions are welcome: "Among non-Catholics, there are two groups I guess. One of these will just ignore the mission and use the core values. A second group, even if they are not Catholic, might appreciate the religious language (...). The religious identity of this place makes them feel very strongly welcomed as a religious person; even though it is the language of another religion." Several interviewees point to the active form of the invitation: "We believe that all our associates need to bring their spirituality into the hospital so that they can bring the best of who they are and give it to our patients, and to one another." One of the institutions coined this invitation as "centered pluralism'. "'Center' denotes the Catholic identity, but also the fact that this identity always is an inclusive one, a complex one, given all of the different types of people we have, and administrators, from atheist, to agnostic, to Muslim, and Jewish, and protestant, and Catholic. So, it says 'welcome' to 
everyone, but is also an invitation to consider what kind of community (...) this is if it has this core and these historical Catholic roots (...). It is an invitation to serious conversations that show results, and benefit people." The existent pluralism within the organization offers a reason for conversation. One wishes to create "a reflective ethos".

5. Ethics: articulation of Catholic beliefs as a moral source for the organization is considered to be a stimulus to all to articulate their own 'moral sources.' It invites non-Catholics and people without religious faith, to consider the question: "if I don't think it is Jesus as the reason, so why do I? It puts that question before people. And when they are just up there, and when they are ungrounded, and the onus is on people to create their own ground, and unless somebody has forcefully stated what he or she thinks his or her own ground is, then there is really less motive to establish one for yourself." Articulation of guiding moral sources and values is also a way "to attribute conscience to an institution". Of particular importance is that articulating the organization's Catholic identity expresses that the institution and all who work there are bound by the ethical views and guidelines of the Catholic Church. For instance: "In obstetrics there might be issues with which non-Catholic physicians will not particularly agree, but in terms of how they manage patients here, they have to comply with the rules and regulations of this Catholic institution." This sometimes might cause dilemmas, for example with the training of future physicians: “... residents should learn all there is to know about abortion, contraception, sterilization, etc. They do not have to do it, but they have to get acquainted to it, to learn the procedures. If we would not do anything, then we have the problem for the future that we would have no ob-gyn physicians anymore that got their education in Catholic medical schools. Now we made a contract with a fertility center. Of course, there were worries about whether or not this was cooperating with evil. But we worked it out in a way that satisfied also the archbishop." In other words, one succeeded in finding a pragmatic solution. A similar result was reached in clinical trials demanding participating research subjects not to become pregnant. According to the Church contraceptives are not allowed. These discordant requirements were reconciled in such a way that the written information to research subjects: "did what the drugs companies needed, saying 'you can not get pregnant and you can not father a child', but in such a way that it was not offensive to the Ethical and Religious Directives of the U.S. Bishops. It said nothing about using contraceptives and stuff like that. So we do not approve of contraceptives, but we do not say anything about using them or not using them." Some interviewees consider discussions on the implications of some ethical views of the Church desirable, but difficult: "One of the challenges 
for a Catholic institution is to invite people to reflect on the experiences of the people, and to say, where are the points of tension between the tough choices people are making, and the guidelines that we have articulated? But that conversation is not taking place, because I do not perceive there is going to be openness. In the U.S. we have many Catholics who believe there is no matter of gravity: that sterilization is the same as abortion, or as artificial contraception."

6. Being prophetic, defined as 'counter cultural'. In market-driven, commercialized, and businesslike healthcare "the mission statement actually does reflect a kind of countercultural aspect of Catholic healthcare." Another explained this as: "We work from an ethical perspective of the common good. That provides our framework for how we think about humane healthcare in this country. Our society, on the contrary, looks from the perspective of negative rights: do not take my guns, or, do not take my rights to make my own choices. The more I can choose, the better it is.” Being prophetic also implicates that: "the Catholic hospital has to commit itself, and reaffirm its commitment to the poor, to those who are suffering, to those on the margin of society." With regard to the growing influence of technology in healthcare, articulation of Catholic identity is a "reminder of the greater good technology has to serve." This prophetic function can only become productive and challenging in combination with ethics and the emphasis on ongoing debates. Taking the example of technology we "need to constantly articulate the greater good, and rearticulate it. This process is part of articulation".

7. Strategy: an articulated Catholic identity can guide the organization in times of great changes like a merger, or of deep crises of, for instance, financial nature. Clearly articulated mission and values statements also provide important strategic tools for guiding ethical decisions within the organization, analyzing actual behaviors and policies, and recruiting and training of people. The strategic reason, therefore, plays a role in all considerations mentioned above. It impels the organization to put efforts in making the mission alive, as part of its strategy: "if there are ways for people to participate and to understand how it applies to them, and if they are constantly helped to see what good work they are doing towards the mission, and they are rewarded for that, a mission can be immensely helpful".

Special attendance in many interviews is given to the language of articulation. There is a tension between an explicitly religious and a more neutral vocabulary. The former makes use of, as Carol Taylor calls it, "Jesus language", like 'healing mission of Jesus', 'according to the Gospel', or, 'the good news'. The latter are limited to references to the historical roots in 
religious communities or persons that founded the organization (2001). A more neutral vocabulary is mostly preferred because of the concern that too religious a vocabulary might put people off. Others wish to be more explicitly religious, because it should be much more expressive for "who we are and how we want our health ministry to be".

The interviews did not disclose to what extent articulation of mission, vision and values really affects daily practice. Estimations of some interviewees vary from optimism, "we bring mission alive in the way we behave on a day-to-day basis" to the skeptic observation that this is "day dreaming". All interviewees, however, are aware that a mere statement of Catholic identity does not suffice. Ideally, articulation of identity should affect day-to-day conduct of employees.

In sum: all interviewees underscore the relevancy of articulating the Catholic identity of the organization, and motivate this by considerations as mentioned above. These considerations are endorsed by organizational theories. These theories confirm that it is relevant for any organization to clearly communicate its identity as a way to keep up its integrity, to inspire its employees and foster internal cohesion, to invite people to commit themselves to the organization, and to guide ethical and strategic behaviors (Collins \& Porras, 1994; Whetten \& Godfrey, 1998; Mills \& Spencer, 2005). A well-articulated mission is an important condition for values-based decision-making (Iltis, 2005).

However, the considerations of the interviewees should also be understood from the perspective of religious reasons. One wants to be explicit about the Catholic identity of the organization: to make clear that this organization is a moral agent at the intersection of Catholicism and healthcare (Sulmasy, 1997). By means of the articulation of this mission, this vision and these values the organization presents itself as a ministry of the Church, committing itself to the Church's religious and ethical views. Second, part of being an institutional moral agent is that articulation of Catholic identity empowers them to behave counter-culturally: by resisting the dominance of the market, the tendencies of depersonalization, and the societal lack of care for the poor and uninsured. Third, being explicit on being Catholic, this term is presented as an inclusive characteristic. Inclusive means that Catholic identity involves inviting associates, employees and students to bring to the organization their own sources of inspiration and their own moral views. Reflection and ongoing discussions on the meanings of the Catholic identity in a pluralistic environment present a constitutive part of this identity. 


\section{Magisterium}

Although identity is articulated by means of stated missions, visions and values on websites, all interviewees agree that it must be shown in institutional policies and guidelines. The organization, advised by its ethics committee, has to articulate its guiding principles and values with regard to different ethical and organizational issues, and the concrete ways of behavior that flow from them. To pursue that, Catholic HCOs carefully observe the moral teaching of the Catholic Church, as this is spread by the Magisterium.

The Magisterium is the teaching authority of the Church in matters of faith and morals. Since the Middle Ages it has become increasingly concentrated in the Church hierarchy, particularly in the pope and bishops (Mahoney, 1989, p. 116-20; Lumen gentium, nr. 25). In the U.S. this teaching has been concretized in the Ethical and Religious Directives for Catholic Health Care Services, fourth edition, published in 2001 by the United States Conference of Catholic Bishops. They represent to Catholic HCOs in the U.S. the main normative framework for articulating their ethical and religious responsibilities.

The Directives themselves can be considered as articulations by the U.S. bishops of what it means to be a Catholic healthcare facility. They specify what a healthcare organization ought to commit itself to, ethically and religiously, in order to be recognized as a Catholic organization. The Directives rely on a rich tradition and numerous authoritative documents offered by the Church, from encyclicals, pastoral letters, papal addresses, to documents of local bishop conferences. ${ }^{3}$

In the Preamble of the Directives health care is presented as a ministry of the Church. To understand this ministry, "one must take into account the new challenges presented by transitions both in the Church and in American society". The Bishops want to meet these challenges by relying on "a body of moral principles (...) that expresses the Church's teaching on medical and moral matters and has proven to be pertinent and applicable to the everchanging circumstances of health care and its delivery." Its purpose is: "first, to reaffirm the ethical standards of behavior in health care that flow from the Church's teaching about the dignity of the human person; second to provide authoritative guidance on certain moral issues that face Catholic health care today." The moral teaching flows "principally from the natural law, understood in the light of the revelation Christ had entrusted to his Church".

The General Introduction offers the theological background for the Catholic health care ministry. It articulates the way health care can be perceived from a Christian perspective. Catholic health care is animated by Christian love. From this perspective it is possible to interpret "healing and compassion as a continuation of Christ's mission", suffering as "a 
participation in the redemptive power of Christ's passion, death, and resurrection", and death "as an opportunity for a final act of communion with Christ". In the course of history, the bishops continue, this religious background has inspired many to engage themselves with the healing mission of the Church: individuals, religious communities, and, increasingly, lay Catholics. Church leaders always had, and still have the responsibility to review medical, technological and social developments in consultation with the medical professionals, to judge these developments "according to the principles of right reason and the ultimate standard of revealed truth, and offer authoritative teaching and guiding about the moral and pastoral responsibilities entailed by the Christian face." The bishops are aware that the Church does not have all the answers to every moral dilemma, but "there are many questions about which she provides normative guidance and direction."

The main part of the Directives is divided into six sections: (1) social responsibility; (2) pastoral and spiritual responsibility; (3) the professionalpatient relationship; (4) issues in care for the beginning of life; (5) issues in care for the dying; (6) forming new partnerships with health care organizations and providers. Every section consists of an introduction, in which the most important theological and ethical principles are set forth, particularly the principle of human dignity, followed by concrete directives.

By elaborating the theological background of Catholic care, the Directives first offer a source of inspiration with which organizations, and many individuals within the organization, can identify. This background provides them with a point of orientation when they start to articulate for themselves what it means to be and to act as a Catholic organization. Second, the Directives offer moral guidelines regarding how a Catholic healthcare organization ought to behave in matters dealt with in the six sections named above. Third, by offering inspiration and guidance the Directives provide religious substance to the seven considerations in the interviews. In particular considerations regarding inspiration, ethics, being prophetic, integrity and strategy derive much of their power and contents from the ecclesiastical perspective on healthcare. With regard to the consideration concerning communication, the focus of the Magisterium is on communicating identity by way of a practice of care that bears witness to the basic principles and values of the Church. In their turn, Catholic HCOs communicate their commitment to the Church's mission by observing the Directives. With regard to the consideration concerning invitation: while in the interviews the articulation of Catholic identity was emphasized as an invitation to all whatever their beliefs are, the Directives focus primarily on Catholics, but also on all responsible for, working in, and making use of 
institutionally based Catholic health care services. Among this group, there might be many non-Catholics, but they are invited to observe the Directives.

The answers that can be derived from the Magisterium to the question whether, and if yes, why it is relevant that Catholic HCOs articulate their identity lie on other levels than the answers provided in the interviews. In the interviews the focus was on creating clarity to all involved with regard to the mission, vision and values that define the Catholic identity of the organization. The Directives offer them a frame of reference to articulate the guiding principles and values behind their organization's ethical and religious practices. Articulation here means: trying to explicate as well as possible what these Directives mean in light of moral experiences of people responsible in and for the organization, and to elaborate these explications in local and feasible policies and guidelines.

The question arises whether such articulation is just repeating the Church's teaching, or whether articulation asks for a more nuanced approach. The former seems to be suggested by the strongly obliging and binding character of the Directives: if Catholic HCOs should operate otherwise, they risk losing the designation 'Catholic'. With regard to the latter we need to deepen our understandings of the concept of articulation.

\section{Charles Taylor on Articulation}

Although Taylor does not deal with Catholic HCOs, from a philosophical perspective he clarifies what articulation is, why it is relevant, how it is valued in modern western culture, and how articulation of religious sources can contribute to modern culture. ${ }^{4}$

Taylor appeals to a broader concept of articulation than we used as a working definition: 'expressing something in a coherent verbal form.' Taylor defines articulation as the process of explicating the goods that underlie moral and spiritual experiences. Articulation is "bringing into awareness that which is unspoken but presupposed" (Abbey, 2000, p. 41). Articulation explicates who individuals having these specific experiences are, and, hence, enriches the way they understand themselves (Joas, 1999, pp. 208-212). It makes them aware of the frameworks that orient their lives and influence their identity. These frameworks are 'horizons of meaning' that help them to take a stance. Frameworks come to them through communities, culture and traditions. Western modern culture itself is the fruit of a sometimes harmonious, sometimes discordant interaction between different traditions: the Greece-Roman heritage, the Christian tradition, Enlightenment and Romanticism. Therefore, to understand the identity of the modern subject, we have to retrieve these traditions and the sources that empowered them. 
By consequence, Taylor 'modernizes' the concept of articulation. We label this as 'modernizing' in the sense that Taylor explicitly questions the position of articulation in modern culture. The label 'modernizing', therefore, is not meant as a value judgment, with its connotations of being better than previous concepts, but as a way to give due right to the place of articulation in modern culture. Taylor's core message is that in contemporary western society the need for articulation of the moral goods that made the achievements of modern culture possible is higher than ever, but the tendencies to declare articulation irrelevant and subjective are stronger than ever.

This is well expressed in the final chapter of his Sources of the Self, where he characterizes this study as a work of liberation:

The intuition which inspired it, which I have recurred to, is simply that we tend in our culture to stifle the spirit (...). We have read so many goods of our official story, we have buried their power so deep beneath layers of philosophical rationale, that they are in danger of stifling. Or rather, since they are our goods, human goods, we are stifling. The intention of this work was one of retrieval. An attempt to uncover buried goods through re-articulation - and thereby to make these sources again empower, to bring the air back again into the half-collapsed lungs of the spirit (1989, p. 520).

In this quotation, several important points of Taylor's philosophical view on articulation in modern culture come together.

First, Taylor positively appraises modern culture because of the goods it achieved in the course of its history and which energized its development: the liberation of the disengaged, autonomous and rational thinking subject; a drive for practical benevolence and alleviation of suffering; a quest for universal justice based on equal human rights.

Second, besides this 'grandeur' of modern culture, there is also 'malaise'. Taylor criticizes modern culture because it favors a neglect of the moral sources of these goods. Modern culture entails strong tendencies to consider these sources as merely optional and subjective. For instance, the predominant naturalistic outlook reduces all human goods and meanings to phenomena that can be described in scientific and behavioral terms and declares terms that do not fit in such a description irrelevant. It reduces terms that express the meaning-dimension of human existence to non-meaning, to the realm of subjective illusions (Smith, 2002, pp. 6-7). Taylor objects to this way of reasoning: a term like 'dignity' may not be described in terms of natural sciences, but it still may be an indispensable term for human beings to make sense of their life and of certain moral feelings.

Third, Taylor argues that re-articulation of moral sources is needed to 
revitalize the spirit of modernity. Smith qualifies this as the 'therapeutic aim' of Taylor $(2002$, p. 7).

In the same chapter of Sources Taylor briefly alludes to Judeo-Christian theism as the most promising framework for him to restore the spirit of modern culture. In a later work, A Catholic Modernity (1999), Taylor more elaborately analyzes the meaning of this religious framework for and in modern culture. That is why Abbey calls this work a complement to Sources (2000, p. 199). Or, as Morgan formulates it: Taylor holds that in western tradition: "God is one of those realities the love of which has empowered people to do and to be good" (1994, p. 53).

The term 'articulation' has no place in Catholic Modernity. Nevertheless, Catholic Modernity clearly is an articulation of what Catholicity means for Taylor, and how it connects to his work as a philosopher of culture. Taylor starts by articulating the meaning of the word 'catholic' (1999, pp. 14-15):

the original word katholou comprises both universality and wholeness; wholeness is a goal of human life that can only be attained by recognition of diversity among human beings; Catholic, therefore, denotes to an 'oneness in diversity', not to a 'sameness'.

Concerning the relation between modern culture and Christianity Taylor distinguishes two aspects. On the one hand, modernity liberated Christian beliefs from Christendom, a "civilization where the structures, institutions, and culture were all supposed to reflect the Christian nature of the society" (1999, p. 17). By breaking with the so-called Christian society modern culture "carried certain facets of Christian life further than they ever were taken or could have been taken within Christendom" (1999, p. 16). As an example, Taylor points to the universal human rights that would not have been possible under Christendom.

On the other hand, however, modern culture started to embrace an 'exclusive humanism', a notion of human flourishing, without recognition of any valid aim beyond this. Any transcendent vision that refers to a dimension beyond life is eliminated. Taylor qualifies this elimination as a denial of human experience. For instance, pain, suffering and death are negations of human flourishing, but can have deep human significance. A culture that denies transcendence, denies what it means to be human. For Taylor, religions are bearers of this transcendent dimension, and they contain important moral sources for people to live a good and meaningful life.

While Catholic Modernity can be considered as an articulation of the contents of Catholic beliefs, at least as Taylor sees them, Varieties of Religion (Taylor, 2002) describes the conditions for the possibility of religion in the secular world of today. In this work Taylor does not use the term 'articulation', but the shifting position of religion in the present-day 
world has its implications in this regard as well.

Varieties sketches the development from a strongly socially and institutionally based religion - here denoted by Taylor as a Durkheimian regime and in Catholic Modernity as the period of Christendom - towards a strongly privatized and experience-based one: a post-Durkheimian situation. In the latter, the emphasis is on authenticity and 'doing your own thing' (2002, p. 84). At the beginning of the $21^{\text {st }}$ century, expressive individualism, already alluded to in Sources and in Ethics of Authenticity (1991) has become a mass phenomenon. Taylor observes several attempts in the U.S. to restore something of the old situation into a kind of neo-Durkheimian model. For instance, together with the moral majority the Christian Right tries to strengthen the idea of 'one nation under God'. He also observes tendencies in the leadership of the Catholic Church, led by the Vatican, to line up with the Christian Right. However, he estimates the possibilities of success as pretty small. What counts in modern world is the motto: "Only accept what rings true to your own inner Self" (Taylor, 2002, p. 101). Therefore, all attempts to settle a new kind of forced conformity will be counterproductive. The spiritual costs will be high: "hypocrisy, spiritual stultification, inner revolt against the Gospel, the confusion of faith and power, and even worse. Even if we had a choice, I'm not sure we wouldn't be wiser to stick with the present dispensation" (p. 114). With regard to articulation Varieties makes clear that, as opposed to previous historical periods, churches may run up against resistances if they try to impose their articulations of what is morally good and meaningful to their members. Many contemporary believers will accept these articulations only in as far as these evoke resonance in their individual experience.

In sum, the philosophical perspective represented by Taylor enables us to modernize the concept of articulation, in the sense of understanding articulation against the backdrops of modern western culture. This culture tends to consider any articulation of what underlies people's moral and spiritual experiences as irrelevant and subjective. Taylor's claim, however, is that subjective experiences cannot be separated from transcending frameworks of goods that come to individuals by communities and traditions. What an individual discovers as a moral good underlying his experiences is compelling because it is not a mere subjective good. It is desired because it is desirable, not vice versa. Christianity is one of the frameworks of western culture, containing goods that contribute to the morals of modern culture. It lost its dominant position. It cannot be imposed anymore on subjects, but only be made accessible and valued through individual experiences. 


\section{Discussion}

As shown above from different perspectives, it is relevant for contemporary Catholic HCOs to articulate their identity. The interviewed persons emphasize that articulating clear missions, visions and values is relevant for organizational-theoretical reasons, and for clearly presenting the organization as a Catholic facility. The Magisterium emphasizes articulation of principles and values in behaviors that flow from the Church's teaching on the dignity of the human person, and offers guidance in present-day moral issues. The Directives apply these teachings to U.S. Catholic healthcare facilities. From a philosophical perspective Taylor argues that in modern culture articulation is a necessary means to create identity, to restore and preserve the moral goods of modern culture, and critically to assess the way these goods are being realized. He believes Christianity to be a major moral source for the goods of modernity, but as opposed to earlier times, modern subjects will be inspired by this source only if and in so far as it connects with their individual experience. We called this a modernized concept of articulation. From this modernized concept two additional reasons will be discussed to answer the question whether and why articulation of Catholic identity is relevant. First, articulation is a means to contribute to the moral teaching of the Church. Second, articulation is a way for Catholic HCOs to contribute to moral dialogues in contemporary pluralistic society.

\section{Catholic HCOs and the Church}

Both Catholic HCOs and the Magisterium emphasize the importance of complying with the Directives. Above we found several strong reasons for this emphasis. The Directives provide Catholic HCOs with a substantive horizon for their goal to continue the healing mission of Jesus. They empower and oblige them to strive for humane and holistic care. They offer a critical potential against treating patients only as medical problems, or only according to their ability to pay. They help to honor the dignity of every patient irrespective of someone's sometimes degrading bodily, mental or social circumstances. In particular, the Directives are valued as a robust moral framework for taking care of the poor and marginalized, despite financial pressures and consequences.

Next to these substantive reasons to observe the Directives, there are practical ones. The Code of Canon Law obliges HCOs to follow them: if they do not, they lose their designation 'Catholic' (Morrisey, 1999). Next, observing the Directives protects their Catholic identity in modes of cooperation with non-Catholic facilities. Further, there is no reason for not 
complying with the Directives, because according to the interviewees all employees appear to be willing to accept them, irrespective of their personal moral and religious convictions. Finally, as some interviewees said, any attempt to a less strict identification with the Directives would evoke a vehement debate with rigid religious groups, in which there is nothing to gain, and much to lose, at least in terms of time.

Nevertheless, a modernized concept of articulation allows us to argue that the magisterial teaching can be enriched by taking into account the numerous moral experiences of people within HCOs with illness, suffering and death, with the vulnerability of life, with questions of meaning, and with hard medical-ethical or organizational-ethical choices. These experiences are gained against the backdrops of the complexities of modern western culture, among others pluralism, secularization, high progress in technology and science, strong dominance of economical thinking. Standing in this culture, experiences gained by and within Catholic HCOs appeal to practical intelligence and conscientious judgments. In many cases the ethics committee represents the forum to discuss the institutional implications of these experiences, and, hence, to develop policies and guidelines.

Articulation will show the plurality of goods, and eventually evils, that are at stake: social, psychological, medical, spiritual, ethical, legal, economical, institutional and so on. Moreover, because many experiences are gained while standing in caring or governing relations with concrete subjects, the question of what one morally owes to this unique man or woman becomes much more pressing. Next, by articulating and rearticulating experiences, they mature in the course of time: they become a built-up property, a fruit of personal or governmental moral growth. An experienced physician, for instance, tries to discern the good of a patient by remembering what has proven to be good in previous comparable situations without duplicating them into the present, by making use of his medical knowledge and by looking forward to what should and could be pursued for this patient in this situation. Experience is the cornerstone of practical wisdom, known as the virtue of prudence, or the recta ratio agibilium, the rectified judgment of things to be done (Henry, 1993, p. 32). Medical and governmental prudence can add indispensable knowledge to the goal of both HCOs and the Church: to realize and sustain good care. Therefore, Catholic HCOs can be considered as communities which can not only be taught by the Church, but which can also teach something to the Church. This is what Mahoney alludes to when he states that the teaching Church - Ecclesia docens - could learn from the learning Church - Ecclesia discens (Mahoney, 1989, p. 222).

There is support for this approach also from within Catholic moral tradition. This tradition acknowledges experience as an indispensable source 
of moral knowledge, in addition to Divine revelation in Scripture and tradition. As is the case with revelation, experiences ask for explanation: why do we experience some things as good, or bad, or admirable, or objectionable? In that sense, the plea of Taylor in favor of articulation is truly Catholic: articulation is a way to acquire moral knowledge by evaluating moral experiences. Catholic moral tradition values this moral knowledge explicitly as a way to get some insight in God's will. The connection between human experience and God's will is made in the Catholic appeal to natural law: “... people (can) discover right and wrong by using their reason and experience to investigate, individually and collectively, the emergent patterns of creation as God is creating them" (Kelly, 2004, p. 84). The 'emergent patterns of creation' reflect God's eternal law of ordering the world to its end. Generally, natural law is described as: "the participation of eternal law in the rational creature" (Curran, 2002, pp. 23-25). In other words, human beings never can know the fullness of God's plans and will with regard to His creation, and they will always be in need of revelation and grace. But their capacities rationally to reflect on their experiences enable them to uncover, provisionally and within their cultural and historical conditions, something of God's intentions. In Catholic tradition, faith is not just passive obedience, but also an active search for intelligibility, fides quaerens intellectum. Faith tells us that God wants our flourishing and fulfillment, and all that jeopardizes these is against God's will. By our reason we can discover what contributes to our flourishing. Therefore, in Catholic tradition, morality and rationality are closely interwoven. God prohibits some acts because they are wrong, i.e., opposed to human happiness; these acts are not wrong because God prohibits them.

The connection of rationality and morality legitimates what Catholic HCOs actually do. They invite all who enter the organization, irrespective of their beliefs, to articulate what they experience as good, right and meaningful, while all have this rational capacity to search for what contributes to human happiness, and what might not. That is why HCOs can be operative as communities, learning by articulation.

To conclude, rationally dealing with concrete experiences provides Catholic HCOs with a source of moral knowledge that is essential to the Church. This source enables them to bring the Magisterial teachings to life, to make them concrete, but also eventually critically to question them. The articulating of identity by Catholic HCOs does not only consist of following the moral teachings of the Magisterium, but also of contributing the ethical validations of practical experiences. Catholic HCOs have to bring in these validations with religious assent to the bishops (Lumen gentium, nr.25), but 
there is no objection in principle that some of the Directives become subjects of debate. If such a debate can be performed in an open and well-argued way, it can contribute to the moral wisdom of the Church. Catholic morality is a living tradition. To sustain that, Catholic HCOs should be considered not only a ministry of the Church, but also as a ministry to the Church.

\section{Catholic HCOs and society}

One of the most visible contributions of Catholic HCOs to American society is their practical and effective care for the poor and marginalized. Two studies, one historical (Kauffman, 1995) and one sociological (Tropman, 2002) show how the outreach toward the poor has marked American Catholic healthcare from its beginnings. Interviewees have repeatedly emphasized that: care for the poor is the touchstone of their identity; abandoning them would severely damage their integrity. While the Catholic hospitals we visited offer concrete care for individuals, member organizations put great efforts in advocacy and healthcare reform, among others at the political level, resisting strong counter forces in the U.S. that want to hold on to the present system.

Underlying the differences between opponents and advocates of the present system are different views about what constitutes humane and just healthcare. While Catholics, inspired by faith, strongly argue in favor of social justice and of the responsibility of a community to its vulnerable members, advocates of the present system show strong adherence to individual responsibility, entrepreneurialism and resistance against too much government interference. Is it possible to reconcile this gap?

Dell'Oro characterizes the postmodern society as a society without a common moral notion (2002). We are, using an expression of Engelhardt, 'moral strangers', because we are all supposed to embrace our own conception of the good life, lacking a commonly shared conception (1996). In his view ethics can only play a regulative function: finding rational agreements and procedures to sustain peace between people and groups with different senses of the moral good. As also Taylor stresses, the advantage of modernity is, that it protects everyone in his own autonomy and freedom to pursue his self-chosen values. The disadvantage is the absence of any substantive dialogue between different senses of the moral good, because any particular sense of the good is considered to be not communal by definition, and should, therefore, not be articulated, at least not in the public domain.

From their specific background, Catholic HCOs can contribute to substantive dialogues about humanity and justice. 
First, as we saw, the Catholic reliance on natural law allows them to argue in rational terms that are, in principle understandable to all people. Reason and faith converge. Faith can empower people to reach out toward the poor and the marginalized. Reason can argue for a concept of justice in which the most disadvantaged people get priority. Thus, the reasonableness of giving this specific meaning to justice can be defended on non-religious terms, but faith can enforce this meaning. Similarly, is it possible to argue on rational and conceivable grounds that the numerous experiences of a hospital with sick and vulnerable people indicate that the humanity of health care cannot be promoted by a one-sided, consumer-driven approach to care, nor with governance of quality by only technological or financial measures. A HCO does not have to be Catholic to start debates on justice and humanity with their employees. But being Catholic it has a strong motive to stimulate such debates. Moreover, it is by such debates, that Catholic identity is created.

Second, a Catholic HCO can be considered as a miniature society, with inside the same moral and religious pluralism as outside: the lack of a common moral notion in society as Dell'Oro argues, presents itself also within the HCOs. This creates specific possibilities. One is described by Iltis: because of the absence of a shared thick understanding of morality in our morally pluralistic society, an organization's mission is its strongest source of moral obligation in our society (Iltis, 2005, pp. 7-8). We consider this an argument in favor of a well-articulated mission and values: it offers the organizations a clear and distinctive point of reference. A second possibility comes to the fore in the interviews and is supported by Taylor. Articulation is an ongoing process of trying to explicate what is presupposed. To do this, we need frameworks. Several interviewees emphasized the dialogues between people with different views as an integral part of articulating Catholic identity. In other words, their 'own' Catholic framework is not meant to limit reflection and dialogue, but is a reason to invite people to reflection and dialogue. Taylor proposes to interpret 'Catholic' as 'oneness in diversity'. Being Catholic at the level of institutions is precisely that: welcoming the diversity of opinion. One of the interviewees expressed the same in the concept of 'centered pluralism'. Everybody is challenged to articulate and rearticulate her and his views, or comments on views of others. In a way it is amazing that, as far as we know, Taylor has always pleaded for substantive moral dialogues in modern society, but he has never explored the possibilities societal institutions like HCOs can offer in this regard. HCOs can construct what MacIntyre calls at the end of After Virtue "local forms of community" to sustain "civility and the intellectual and moral life" (MacIntyre, 1997, p. 263). Catholic HCOs are communities where such explorations can take place. What they discuss 
regarding the meanings of humanity and justice in healthcare and how they discuss these items can play an exemplary role in pluralistic society.

\section{Conclusion}

We raised the question whether, and if yes, why it is relevant for contemporary Catholic healthcare organizations (HCOs) to articulate their Catholic identity. We derived answers to this question from an organizational, an ecclesiastical and a philosophical perspective. Although our focus was on the U.S., most of the reasons we found in favor of articulation of Catholic identity seem to be applicable to other countries as well. These reasons were grounded on organizational theory; on clearly communicating its Catholic identity inside and outside the organization; on embodying Catholic identity in diverse religious and ethical behaviors areas in coherence with the Magisterial teachings of the Church; and on the necessity of articulation as a means to create identity and to (re-)vitalize the moral sources of modern culture.

From Taylor's philosophy we derived a concept of articulation that we labeled as 'modernized'. Based on this modernized concept, we discussed two additional reasons to articulate Catholic identity. By explicating the substantial moral sources and moral goods underlying concrete experiences with health, illness, suffering and tough organizational choices, Catholic health care organizations can offer a critical and coherent contribution to the Church and to society. The objective of this contribution is a practice of humane and just care, in accordance with the demands of human dignity. By and within this practice, and the efforts of Catholic HCOs to realize it, their identity comes alive.

Finally, as we emphasized in the beginning, articulation is only one way to embody Catholic identity. It makes people aware of what is done and why it is done. It enables Catholic identity to become a continuously developing characteristic of a healthcare organization, and a source of critical selfawareness. At the same time, it demonstrates that the Catholic tradition is a living tradition. Ultimately, articulation is a means to the end of good care practices. It is in these practices that Catholic identity ought to show itself.

\section{NOTES}

1 All websites are accessed in the period October-November 2005. For reasons of confidentiality, we removed the names of the HCOs and other information that could lead to identification. 
2 Again, for reasons of confidentiality and privacy all quotations are presented in such a way, that the author of the quotation is not identifiable. In so far as there is suspicion of a link between the author of a certain interview quotation and a specific $\mathrm{HCO}$, we emphasize that the views expressed are intended only to convey the personal opinions of those persons interviewed, and should not be taken to be indicative of the policy of any particular organization.

3 Some of the most influential Vatican documents in this field are:

- Pope Paul VI, Humanae Vitae: On the Regulation of Birth, Encyclical, 1968;

- Sacred Congregation of the Doctrine of the Faith, Declaration on Procured Abortion, 1974;

- Sacred Congregation of the Doctrine of the Faith, Declaration on Euthanasia,1980;

- Pope John Paul II, Salvifici Doloris: On the Christian Meaning of Human Suffering, Apostolic letter, 1984;

- Congregation for the Doctrine of the Faith, Instruction on Respect for Human Life in its Origin and on the Dignity of Procreation Donum Vitae: Replies to Certain Questions of the Day, 1987;

- Pope John Paul II, Sollicitudo Rei Socialis: On Social Concern. Encyclical, 1988.

All documents are available on the website of the Vatican: www.vatican.va.

4 For a more expanded study on Taylor's view on articulation see Pijnenburg and Ten Have (2004).

\section{REFERENCES}

- (1964). Lumen gentium, Dogmatic constitution on the Church. November 21.

Abbey, R. (2000). Charles Taylor. Teddington: Acumen.

Catholic Health Association (2007). [On-line] Available: www.chausa.org (accessed on May 10, 2007).

Collins, J. C. \& Porras, J. I. (1994). Built to last. Successful habits of visionary companies. New York: HarperCollins Publishers.

Curran, C. E. (2002). Catholic social teaching. A historical, theological, and ethical analysis. Washington, D.C.: Georgetown University Press.

Dell'Oro, R. (2002). Theological discourse and the postmodern condition: The case of bioethics. Medicine, Health Care and Philosophy. A European Journal, 5(2): 127-36. 
Dougherty, C. (2004). Ethical dimensions of trusteeship on the boards of Catholic hospitals and systems. In: B. Jennings et al. (eds.), The ethics of hospital trustees. Washington, D.C.: Georgetown University Press, pp. 181-99.

Engelhardt, Jr., H. T. (1996). The foundation of bioethics, second edition. New York: Oxford University Press.

Glossary (2007). Paul Niven's balanced scorecard academy powered by QPR. [On-line] Available: www.balancedscorecard.biz/Glossary.pdf; (accessed on 7 May, 2007).

Halman, L., Luijkx, R. \& Zundert, M. V. (2005). Atlas of European values. Leiden: Koninklijke Brill NV; Tilburg: Tilburg University Press.

Henry, C. W. (1993). The place of prudence in medical decision making. Journal of Religion and Health, 32(1), pp. 27-37.

Iltis, A. S. (2005). Values based decision making: organizational mission and integrity. HEC Forum, 17(1), 6-17.

Joas, H. (1999). Die Entstehung der Werte. Frankfurt am Main: Suhrkamp Verlag.

Kauffman, C. J. (1995). Ministry and meaning. A religious history of Catholic health care in the United States. New York: Crossroad Publishing Company.

Kelly, D. F. (2004). Contemporary Catholic health care ethics. Washington, D.C.: Georgetown University Press.

MacIntyre, A. (1997). After virtue. A study in moral theory, second edition. London: Duckworth \& Co. Ltd.

Mahoney, J. (1989). The making of moral theology. Oxford: Oxford University Press, Clarendon Paperback.

Merger Watch (2007). [On-line] Available: www.mergerwatch.org/ about.html (accessed on September 27, 2007).

Mills, A. E. \& Spencer, E. M. (2005). Values based decision making: a tool for achieving the goals of healthcare. HEC Forum, 17(1), 18-32.

Morgan, M. L. (1994). Religion, history, and moral discourse. In: J. Tully (ed.), Philosophy in an age of pluralism. The philosophy of Charles Taylor in question. Cambridge: Cambridge University Press, pp. 49-66.

Morrisey, F. (1999). Catholic identity in a challenging environment. Health Progress, 80(6), 38-42.

Smith, N. S. (2002). Charles Taylor. Meaning, morals, and modernity. Cambridge: Polity Press i.a.w. Blackwell Publishers.

Sulmasy, D. (1997). Institutional conscience and moral pluralism in health care. New Theology Review, 10 (4), 5-21.

Taylor, C. (1989). Sources of the self. The making of the modern identity. Cambridge: Cambridge University Press. 
Taylor, C. (1991). The ethics of authenticity. Cambridge: Harvard University Press.

Taylor, C. (1999). A Catholic modernity? In: J.L. Heft (ed.), A Catholic modernity? Charles Taylor's Marianist award lecture. New York: Oxford University Press, pp. 13-38.

Taylor, C. (2002). Varieties of religion today. William James revisited. Cambridge: Harvard University Press.

Taylor, CFSN, Sr. C. (2001). Roman Catholic health care identity and mission: Does Jesus language matter? Christian Bioethics, 7 (1), 29-47.

Tropman, J. E. (2002). The Catholic ethics and the spirit of community. Washington, D.C.: Georgetown University Press.

Pellegrino, E. D. (2004). The present and future importance of Catholic health care in the United States. In: K. McMahon, STD (ed.), Moral issues in Catholic health care. Wynnewood: Saint Charles Borromeo Seminary, pp. 1-18.

Pijnenburg, M. \& Have, H. ten (2004). Catholic hospitals and modern culture. The National Catholic Bioethics Quarterly, 4(1), 73-88.

United States Conference of Catholic Bishops (2001). Ethical and religious directives for Catholic health care services, fourth edition, June 15, 2001. [On-line] Available: www.usccb.org/bishops/directives.shtml (accessed at February 17, 2007).

Whetten, D. \& Godfrey, P. (1998). Identity in organizations. Building theory through conversations. Thousand Oaks: Sage Publications.

Wills, G. (1990). Under God. Religion and American politics. New York: Simon \& Schuster.

Zuckerman, P. (2004). Secularization: Europe - yes, United States - no: why has secularization occurred in Western Europe but not in the United States? An examination of the theories and research. Skeptical Inquirer, March-April. [On-line] Available: www.findarticles.com /p/ articles / mi _m2843 (accessed on October 13, 2005). 